Research

Open Access

\title{
Effects of salbutamol on exhaled breath condensate biomarkers in acute lung injury: prospective analysis
}

\author{
Oriol Roca ${ }^{1,2,3}$, Susana Gómez-Ollés ${ }^{2,3}$, Maria-Jesús Cruz ${ }^{2,3}$, Xavier Muñoz ${ }^{2,3}$, Mark JD Griffiths ${ }^{4}$ \\ and Joan R Masclans 1
}

\begin{abstract}
1 Intensive Care Department (General Area), Hospital Universitari Vall d'Hebron, Pg. Vall d'Hebron 119-129, C.P. 08035 Barcelona, Spain 2Pulmonology Department, Hospital Universitari Vall d'Hebron, Pg. Vall d'Hebron 119-129, C.P. 08035 Barcelona, Spain

${ }^{3}$ Ciber Enfermedades Respiratorias (CIBERES). Carretera de Sóller Km.12-Fundació Caubet-Cimera, C.P. 07110, Bunyola (Mallorca), Spain

${ }^{4}$ Unit of Critical Care, Royal Brompton Campus, Imperial College London, Sydney Street, London, SW3 6NP, UK
\end{abstract}

Corresponding author: Oriol Roca, 36416org@comb.es

Received: 26 Mar 2008 Revisions requested: 17 Apr 2008 Revisions received: 8 May 2008 Accepted: 30 May 2008 Published: 30 May 2008

Critical Care 2008, 12:R72 (doi:10.1186/cc6911)

This article is online at: http://ccforum.com/content/12/3/R72

(c) 2008 Roca et al.; licensee BioMed Central Ltd.

This is an open access article distributed under the terms of the Creative Commons Attribution License (http://creativecommons.org/licenses/by/2.0), which permits unrestricted use, distribution, and reproduction in any medium, provided the original work is properly cited.

\begin{abstract}
Introduction The benefits of $\beta$-adrenergic stimulation have been described in acute lung injury (ALI), but there is still no evidence of its anti-inflammatory effect in these patients. Biomarkers in exhaled breath condensate (EBC) were used to study the effects of salbutamol on lung inflammation in mechanically ventilated patients with ALI.
\end{abstract}

Methods EBC was collected before and 30 minutes after administration of inhaled salbutamol $(800 \mu \mathrm{g})$. The following parameters were measured in the samples: volume obtained, conductivity, $\mathrm{pH}$ after helium deaeration, and concentration of nitrites, nitrates and 8-isoprostane. The leukotriene $B_{4}$ concentration was measured after sample lyophilization and reconstitution. Results are expressed as the median (interquartile range).

Results EBC was obtained from six ALI patients, with a median age of 56 ( 46 to 76 ) years. At the time of EBC collection, the Lung Injury Score was 3 (2.3 to 3.1) and the $\mathrm{PaO}_{2} / \mathrm{F}_{1} \mathrm{O}_{2}$ ratio was 133 (96 to 211$) \mathrm{mmHg}$. A significant increase in deaerated
EBC $\mathrm{pH}$ was observed after salbutamol administration (7.66 (7.58 to 7.75 ) versus 7.83 (7.67 to 7.91$), P=0.028$ ). Trends toward decreased nitrosative species (18.81 (13.33 to 49.44) $\mu \mathrm{M}$ versus 21.21 (8.07 to 29.83) $\mu \mathrm{M}, P=0.173$ ) and decreased 8-isoprostane concentration (11.64 (7.17 to 17.13) $\mathrm{pg} / \mathrm{ml}$ versus 6.55 (4.03 to 9.99 ) $\mathrm{pg} / \mathrm{ml}, P=0.068$ ) were detected. No changes in leukotriene $B_{4}$ concentration were found (1.58 (0.47 to 3.57$) \mathrm{pg} / \mathrm{ml}$ versus 2.06 (1.01 to 3.01$) \mathrm{pg} /$ $\mathrm{ml}, P=0.753)$.

Conclusion EBC analysis is a noninvasive technique that can be used to monitor ventilated patients. In EBC from a small cohort of patients with ALI, inhaled salbutamol significantly decreased airspace acidosis, a marker of inflammation, and was associated with a trend toward decreased markers of nitrosative and oxidative stress.

\section{Introduction}

Collection of exhaled breath condensate (EBC) is a novel noninvasive means of obtaining lower respiratory tract samples that can be repeated several times with short intervals between sampling [1]. The collection devices can be used in patients breathing spontaneously as well as in mechanically ventilated patients. The technique is based on the hypothesis that particles exhaled in breath reflect the composition of the alveolar lining fluid. Inflammatory markers and several mole- cules can be detected in EBC. The concentration of these mediators is influenced by lung diseases and may be modulated by therapeutic interventions; hence, EBC analysis could be a useful, noninvasive technique for monitoring the evolution of lung diseases.

Several studies have reported mediator changes in EBC samples from acute respiratory distress syndrome (ARDS) patients, such as an increased hydrogen peroxide concentra-

$\mathrm{ALI}=$ acute lung injury; $\mathrm{ARDS}=$ acute respiratory distress syndrome; $\mathrm{EBC}=$ exhaled breath condensate; $\mathrm{IL}=$ interleukin; 8-isoPGF $2 \alpha=8$-isoprostane; $\mathrm{LTB}_{4}=$ leukotriene $\mathrm{B}_{4} ; \mathrm{PaO}_{2} / \mathrm{F}_{1} \mathrm{O}_{2}=$ arterial oxygen partial pressure:fraction of inspired oxygen, ratio 
tion [2] and an increased 8-isoprostane (8-isoPGF ${ }_{2 \alpha}$ ) concentration in patients with, or at risk for, ARDS as compared with normal control subjects [3]. A correlation between the EBC nitrite concentration and the tidal volume has been found in acute lung injury (ALI) patients, possibly reflecting ventilatorassociated lung injury [4]. The EBC $\mathrm{pH}$ has been related to the extent of lung injury, and a good correlation with EBC IL-6 and IL-8 concentrations has been observed [5]. In addition, ALI and ARDS patients show higher EBC cytokine concentrations than healthy volunteers [6].

The potential benefits of $\beta$-adrenergic stimulation in ALI include epithelial protection, decreased neutrophil chemotaxis and activation, lower proinflammatory cytokine production, increased surfactant secretion, improved respiratory mechanics, and increased alveolar fluid clearance [7-9]. No studies have been conducted, however, to determine the possible anti-inflammatory effect of $\beta$-adrenergic drugs in ALI patients by measuring biomarkers in EBC or plasma, even though studies in healthy volunteers have suggested that salbutamol may be effective for this purpose $[10,11]$.

The aim of the present study was to use EBC biomarkers to investigate whether salbutamol has anti-inflammatory effects on the lungs of mechanically ventilated patients with ALI.

\section{Materials and methods Study population}

Mechanically ventilated adult patients who met the criteria for ALI according to the American-European Consensus Conference definition [12] were eligible for participation in the study. All patients were ventilated according to the ARDS Network low tidal volume (ARMA)study protocol [13]. The exclusion criteria were age $<18$ years, chronic obstructive pulmonary disease with chronic $\beta$-adrenergic treatment, $\beta$-adrenergic agents taken within 12 hours before enrollment, unstable asthma, coronary artery disease with a contraindication for $\beta$ agonist administration, surgical procedure required within 24 hours before enrollment, immunosuppressive therapy (steroids $>20 \mathrm{mg} /$ day, chemotherapy, or other immunosuppressive agents within 2 weeks), administration of nonsteroidal anti-inflammatory drugs, pregnancy, participation in other interventional trials $\mathbf{3 0}$ days prior to enrollment, or allergy to salbutamol.

The study was approved by the local Ethics Committee and informed consent was obtained from the patients' family before inclusion.

\section{Clinical data}

Ventilatory parameters, pulmonary gas exchange, the Lung Injury Score [14], and the Sequential Organ Failure Assessment score [15] were recorded before starting EBC collection. The presence of infection was investigated before starting treatment. Electrocardiographic, hemodynamic, and respiratory parameters were monitored during EBC collection and salbutamol administration.

\section{Exhaled breath condensate samples}

Samples were collected before and 30 minutes after administration of inhaled salbutamol $(800 \mu \mathrm{g}$ : measured $\mathrm{pH}, 7.0)$ by metered-dose inhaler (Salbutamol Aldo-Unión EFG, Esplugues de Llobregat, Spain). EBC was collected using a commercially available condenser (EcoScreen; Jaeger, Würzburg, Germany), fitted with an adapter for mechanically ventilated patients (VentAdapter; FILT Lung and Chest Diagnostic $\mathrm{GmbH}$, Berlin, Germany). The heat and moisture exchanger was removed 1 minute before starting EBC collection. The $\mathrm{EBC}$ condenser cooled exhaled breath at $-20^{\circ} \mathrm{C}$. The collector temperature was measured at the beginning of collection. The EBC ( 1 to $2 \mathrm{ml}$ ) was collected in 25 to 45 minutes, depending on the patient's volume per minute. Samples were transferred immediately to the laboratory for processing.

Each EBC sample was divided into $500 \mu$ aliquots in two to four polypropylene tubes (Biosigma, Venice, Italy). The aliquots, used for the measurement of nitrites, nitrates, 8isoPGF ${ }_{2 \alpha}$ and leukotriene $\mathrm{B}_{4}\left(\mathrm{LTB}_{4}\right)$, were immediately stored at $-70^{\circ} \mathrm{C}$, and were analyzed within 1 month after collection. The other aliquots were used to measure the conductivity and $\mathrm{pH}$ before and after deaeration.

\section{pH and conductivity measurement}

The $\mathrm{pH}$ was measured in one of the aliquots immediately after deaeration with helium ( $350 \mathrm{ml} / \mathrm{min}$ for 10 minutes), using a model GLP 21 calibrated pH meter (Crison Instruments SA, Barcelona, Spain) with an accuracy of $\pm 0.01 \mathrm{pH}$. Conductivity was measured immediately after collection using a model COND 510 conductivity meter (XS Instruments; OptoLab, Milan, Italy) with an accuracy of $\pm 1 \%$.

\section{Exhaled breath condensate nitrite/nitrate, 8-isoprostane and leukotriene $B_{4}$ concentrations}

The nitrate/nitrite concentration was determined by a colorimetric assay based on the Griess reaction in which sample duplicates were reacted with Griess reagent (Cayman Chemical, Ann Arbor, MI, USA) and were measured at $540 \mathrm{~nm}$ absorbance with a microplate reader. The assay sensitivity was $1 \mu \mathrm{M}$ for nitrite and $2.5 \mu \mathrm{M}$ for nitrate.

The EBC 8-isoPGF ${ }_{2 \alpha}$ concentration was determined by a competitive enzyme immunoassay using a commercially available kit (Cayman Chemical). The assay sensitivity was $4 \mathrm{pg} / \mathrm{ml}$.

The $\mathrm{LTB}_{4}$ concentration in EBC samples was determined by a $\mathrm{LTB}_{4}$ EIA kit (Cayman Chemical) after sample lyophilization and reconstitution. The assay sensitivity was $13 \mathrm{pg} / \mathrm{ml}$. 


\section{Statistical analysis}

Descriptive statistics are expressed as the median (interquartile range). Differences between groups were analyzed by the Wilcoxon test. Spearman's rank correlation coefficient was applied to determine correlations between the various parameters studied. Significance was set at $P<0.05$ (two-sided). SPSS 13.0 for Windows (SPSS, Inc., Chicago, IL, USA) was used for the statistical analyses.

\section{Results}

\section{General characteristics of the study population}

Six patients (four males, two females) aged 56 (46 to 76) years were studied; none were current smokers. The origin of ALI was intrapulmonary in five patients. The etiologies included pneumonia (four patients), smoke inhalation (one patient), and extrapulmonary sepsis (one patient). Before EBC collection, patients had been mechanically ventilated for 55 (37 to 76) hours, and evolution of lung injury was 58 (32 to 79 ) hours.

At the time of EBC collection, the patients' Lung Injury Score was 3 (2.3 to 3.1) and the $\mathrm{PaO}_{2} / \mathrm{F}_{1} \mathrm{O}_{2}$ ratio was 133 (96 to 211) $\mathrm{mmHg}$. The Sequential Organ Failure Assessment score was 9 (5.8 to 12). No significant changes were observed in the plateau pressure (27 (24 to 30 ) $\mathrm{cmH}_{2} \mathrm{O}$ versus 26 (21 to 29) $\left.\mathrm{cmH}_{2} \mathrm{O}, P=0.416\right)$ or in the intrinsic positive end-expiratory pressure $(0.5$ (0 to 2.5$) \mathrm{cmH}_{2} \mathrm{O}$ versus 0.25 (0 to 0.9 ) $\mathrm{cmH}_{2} \mathrm{O}, P=0.18$ ) following salbutamol administration.

Pulmonary gas exchange values before and after salbutamol inhalation are summarized in Table 1. There were no adverse events related to EBC collection or salbutamol inhalation.

\section{Exhaled breath condensate measurements}

The main results of EBC measurement are presented in Table 2. Before salbutamol administration, there was a significant correlation between postdeaeration $\mathrm{pH}$ and nitrite levels $(r=-$ $0.899, P=0.015)$. A positive correlation was also found between nitrosative species and $\mathrm{LTB}_{4}(r=0.943, P=0.005)$, and between nitrosative species and 8-isoPGF ${ }_{2 \alpha}(r=0.9, P=$ 0.037). The tidal volume, the $\mathrm{PaO}_{2} / \mathrm{F}_{1} \mathrm{O}_{2}$ ratio, and the Lung Injury Score showed no correlations with EBC pH or biomarkers.

Deaerated $\mathrm{pH}$ values were higher after salbutamol inhalation than before $(P=0.028)$. Total nitrates and $\mathrm{LTB}_{4}$ were detectable in EBC samples from all patients, whereas nitrites and 8isoPGF ${ }_{2 \alpha}$ were detectable in five patients. A tendency to decreased nitrosative species and decreased 8-isoPGF $\mathrm{F}_{2 \alpha}$ concentrations was observed after salbutamol inhalation $(P=$ 0.173 and $P=0.068$ ).

\section{Discussion}

In the present small study, we report the apparent anti-inflammatory effects of an inhaled $\beta$-adrenergic agent in ALI patients on biomarkers in EBC. A significant increase was observed in the deaerated EBC $\mathrm{pH}$ after salbutamol inhalation, as well as a trend to decreased total nitrate and 8 -isoPGF ${ }_{2 \alpha}$ concentrations.

The $\mathrm{pH}$ of the airway lining fluid is the result of a balance between different buffer systems and the production and release of acids and bases in the airways [1]. In a healthy airway, several factors favor acidification of the airway lining fluid, such as secretion by alveolar type 2 cells and macrophages, necrosis of macrophages and the alveolar carbon dioxide partial pressure $\left(\mathrm{pCO}_{2}\right)$. The $\mathrm{pH}$ becomes more alkaline in the proximal airway owing to airway epithelial cell enzyme systems, ion channel activity and buffering proteins [16]. The normal range of EBC $\mathrm{pH}$ for healthy subjects is 7.4 to 8.8 [1].

Few studies have reported EBC $\mathrm{pH}$ values for mechanically ventilated patients. In otherwise healthy patients undergoing lung resection for cancer, the mean EBC $\mathrm{pH}$ obtained using RTubes $^{\mathrm{TM}}$ was 7.8 [17]. Another study of patients undergoing cardiothoracic surgery that used the same EBC collection device reported $\mathrm{pH}$ values between 5 and 7 [18]. Finally, using

Table 1

Pulmonary gas exchange values before and after salbutamol administration

\begin{tabular}{|c|c|c|c|}
\hline & Salbutamol & & $P$ value \\
\hline & Before administration & After administration & \\
\hline $\mathrm{PH}$ & $7.45(7.39$ to 7.51$)$ & $7.43(7.37$ to 7.46$)$ & 0.080 \\
\hline $\mathrm{PaO}_{2} / \mathrm{F}_{1} \mathrm{O}_{2}$ ratio $(\mathrm{mmHg})$ & $133(96$ to 211$)$ & $140(102$ to 154$)$ & 0.600 \\
\hline Partial pressure of arterial carbon dioxide $\left(\mathrm{PaCO}_{2}\right)(\mathrm{mmHg})$ & 41 (37 to 48$)$ & 43 (39 to 50$)$ & 0.072 \\
\hline Bicarbonate $\left(\mathrm{HCO}_{3}^{-}\right)(\mathrm{mmol} / \mathrm{l})$ & 26.5 (23.5 to 32.7$)$ & 26 (24 to 32.3$)$ & 0.680 \\
\hline Base excess (BE) (mmol/l) & $2.4(-1.4$ to 9.1$)$ & $2.2(-0.6$ to 8.7$)$ & 0.916 \\
\hline Arterial oximetry $\left(\mathrm{SaO}_{2}\right)(\%)$ & 97 (96 to 98$)$ & 97 (96 to 98$)$ & 1.000 \\
\hline
\end{tabular}

Results expressed as the median (interquartile range). 
Table 2

Exhaled breath condensate biomarkers before and after salbutamol administration

\begin{tabular}{|c|c|c|c|}
\hline & Salbutamol & & $P$ value \\
\hline & Before administration & After administration & \\
\hline $\mathrm{pH}$ after deaeration & 7.66 (7.58 to 7.75$)$ & 7.83 (7.67 to 7.91$)$ & 0.028 \\
\hline Conductivity ( $\mu \mathrm{S})$ & 74 (25.4 to 166$)$ & 64 (41.1 to 293.5$)$ & 0.465 \\
\hline Leukotriene $\mathrm{B}_{4}(\mathrm{pg} / \mathrm{ml})$ & $1.58(0.47$ to 3.57$)$ & $2.06(1.01$ to 3.01$)$ & 0.753 \\
\hline Nitrite $(\mu \mathrm{M})+$ nitrate $(\mu \mathrm{M})$ & $18.81(13.33$ to 49.44$)$ & 21.21 (8.07 to 29.83 ) & 0.173 \\
\hline 8-isoprostane (pg/ml) & $11.64(7.17$ to 17.13$)$ & 6.55 (4.03 to 9.99$)$ & 0.068 \\
\hline
\end{tabular}

Results expressed as the median (interquartile range).

the EcoScreen in mechanically ventilated patients, a mean deaerated EBC $\mathrm{pH}$ value of 5.98 was reported [5]. In that study, however, the $\mathrm{pH}$ measurements were performed at $10^{\circ} \mathrm{C}$ - in contrast to our study, where the $\mathrm{pH}$ was measured when the sample reached room temperature. The condensing equipment and the condensing and measuring temperatures used may all affect the EBC $\mathrm{pH}$ [19], making comparison of reported results between studies difficult.

Three essential mechanisms in ALI patients may lead to EBC acidification [5]. Firstly, lactate production is increased in hypoxia due to continuing glucose utilization. Secondly, there is a reduced local buffer capacity secondary to inhibition of glutaminase activity [20]. Finally, neutrophilic inflammation and oxidative stress in the airspace associated with multiple lung diseases [21] has been associated with acidification of EBC that was reversible with anti-inflammatory therapy.

EBC acidity is an important marker of lung inflammation, and the higher $\mathrm{EBC} \mathrm{pH}$ values detected after a single dose of salbutamol in our study could be related to an anti-inflammatory effect of $\beta$-adrenergic stimulation in ALI patients. No significant changes in the partial pressure of arterial carbon dioxide $\left(\mathrm{PaCO}_{2}\right)$ after salbutamol inhalation were observed, which means that changes observed in the $\mathrm{pH}$ were not caused by changes in alveolar ventilation. In a recent study, EBC $\mathrm{pH}$ values were continuously monitored in mechanically ventilated patients, and EBC acidification was observed even before the clinical alteration appeared [22]. This phenomenon has also been observed in studies on chronic obstructive pulmonary disease [22] and asthma exacerbations [20,21], bronchiestasis [21], cystic fibrosis [23], and other studies on ALI [5,18]. To date there are no reports investigating the possible antiinflammatory effect of $\beta$-adrenergic drugs in ALI patients. The anti-inflammatory effect of this agent has been demonstrated, however, in healthy volunteers undergoing prior lipopolysaccharide inhalation, which generates a neutrophil influx and degranulation into the lungs. This effect was strongly reduced by salmeterol inhalation [10]. Likewise, salbutamol inhibits platelet-activating factor-induced pulmonary neutrophil sequestration [11].
Experimental data have shown that $\beta$-adrenergic stimulation can significantly decrease proinflammatory cytokine expression, chemokine mRNA induction, and the resultant neutrophil lung infiltrate in an animal model of endotoxin-induced ALI [24]. More recently, Perkins and colleagues [25] demonstrated that salbutamol can stimulate epithelial repair, and the results of another retrospective study suggest that high doses of salbutamol are associated with shorter duration and less severe acute lung injury [26]. In addition to this potential antiinflammatory effect, there may be beneficial mechanical effects and improved reabsorption of pulmonary edema. Effectively, it has been shown that airway resistance and peak and plateau pressures decrease, and that dynamic compliance improves with salbutamol administration [27-29]. Moreover, some studies have demonstrated that $\beta$-adrenergic stimulation increases alveolar fluid clearance $[9,30,31]$, by stimulating the apical amiloride-sensitive sodium channel and the baseline $\mathrm{Na}^{+} / \mathrm{K}^{+}$-ATPase alveolo-capillary channel, which allows passage of water from the alveoli to the interstitium [32]. Nevertheless, a direct effect of salbutamol inhalation on EBC $\mathrm{pH}$ cannot be ruled out, even though there is no published evidence indicating this fact and the measured salbutamol $\mathrm{pH}$ was neutral.

A trend towards decreased nitrosative species and 8isoPGF $_{2 \alpha}$ was observed after a single dose of salbutamol. Few studies to date have used EBC in mechanically ventilated patients, particularly in ALI patients [3-6,18,22]. Several inflammatory mediators are present in EBC samples, such as interleukins [5,6], leukotrienes [18], reactive oxygen [3] and nitrogen species [4]. Pulmonary nitric oxide production has been shown to be stimulated by mechanical forces [33]. Release of pulmonary nitric oxide species may reflect alveolar distension and inflammation. In fact, EBC nitrite has been closely correlated to tidal volume, and the EBC nitrite and tidal volume ratio has been strongly correlated to the extent of lung injury, using the oxygenation criteria of the consensus definition or the Lung Injury Score [4]. The nitrosative species decrease observed in the present study could therefore be related to some improvement in mechanical stress in these patients, even though no significant changes in plateau pres- 
sure or intrinsic positive end-expiratory pressure were observed, probably because their values before salbutamol inhalation were normal. 8-isoPGF $2 \alpha$ is a marker of oxidative stress [34] in patients with asthma, interstitial lung disease, chronic obstructive pulmonary disease, cystic fibrosis and ALI $[1,3]$. Our results suggest that salbutamol inhalation may play a role in preventing the lipid peroxidation that occurs in ALI and ARDS patients, although further study is needed to confirm this hypothesis.

No changes were seen in the EBC $\mathrm{LTB}_{4}$ concentration after salbutamol administration, a finding that may have been affected by the small sample size and by the fact that only single-dose administration was tested.

The present study is preliminary and has some limitations related to the EBC technique and to the small size of the patient cohort. The samples obtained are extremely diluted and most biomarkers are at the low end of assay sensitivity. A potential option to overcome this problem is to increase the concentration of the samples, as was done with $\mathrm{LTB}_{4}$, with lyophilization being one of the methods of choice $[1,5,6]$. Furthermore, the relative contribution of the lower respiratory tract versus alveoli in the final composition of the sample obtained is unknown. Nevertheless, in mechanically ventilated patients we minimize one of the main problems of this technique, which is salivary contamination of the sample.

\section{Conclusion}

In summary, EBC is a novel technique that can be used to monitor ventilated patients and to assess therapeutic interventions. In the future, it may have an important role in monitoring ALI patients because it is completely noninvasive and no adverse effects have been described to date. In our small series, inhaled salbutamol significantly increased the deaerated $\mathrm{EBC} \mathrm{pH}$ and showed a tendency to decrease nitrosative species and the 8-isoPGF ${ }_{2 \alpha}$ concentration in patients with ALI.

\section{Key messages \\ - $\quad$ EBC is a novel technique that can be used to monitor airspace inflammation in ventilated patients and to assess therapeutic interventions. \\ - In ALI patients, higher EBC pH values were detected after a single dose of inhaled salbutamol, which could be related to an anti-inflammatory effect of $\beta$-adrenergic stimulation. \\ - A trend to decreased nitrosative species and 8- isoPGF $_{2 \alpha}$ was observed after a single dose of salbuta- mol, suggesting that it may play a role in preventing the lipid peroxidation that occurs in ALI and ARDS patients.}

\section{Competing interests}

The authors declare that they have no competing interests.

\section{Authors' contributions}

OR conceived the study, carried out the sample collection, performed the statistical analysis and drafted the manuscript. SG-O was involved in the design of the study, carried out the EBC sample measurements and reviewed the manuscript critically for intellectual content. M-JC and XM were involved in the design of the study and reviewed the study critically for important intellectual content. MJDG reviewed the study critically for important intellectual content. JRM conceived the study, carried out the sample collection and gave the final approval to the version to be published.

\section{Acknowledgements}

The present study was funded in part by a grant from Institut-Fundació de Recerca Vall d'Hebron.

\section{References}

1. Horváth I, Hunt J, Barnes PJ, Alving K, Antczak K, Baraldi E, Becher G, van Beurden WJ, Corradi M, Dekhuijzen R, Dweik RA, Dwyer T, Effros R, Erzurum S, Gaston B, Gessner C, Greening A, Ho LP, Hohlfeld J, Jöbsis Q, Laskowski D, Loukides S, Marlin D, Montuschi $P$, Olin AC, Redington AE, Reinhold P, van Rensen EL, Rubinstein I, Silkoff P, ATS/ERS Task Force on Exhaled Breath Condensate, et al:: Exhaled breath condensate: methodological recommendations and unresolved questions. Eur Respir J 2005, 26:523-548.

2. Baldwin SR, Simon RH, Grum CM, Ketai LH, Boxer LA, Devall LI: Oxidant activity in expired breath of patients with adult respiratory distress syndrome. Lancet 1986, 1:11-14.

3. Carpenter CT, Price PV, Christman BW: Exhaled breath condensate isoprostanes are elevated in patients with acute lung injury or ARDS. Chest 1998, 114:1653-1659.

4. Gessner C, Hammerschmidt S, Kuhn H, Lange T, Engelmann L, Schauer J, Wirtz $\mathrm{H}$ : Exhaled breath condensate nitrite and its relation to tidal volume in acute lung injury. Chest 2003, 124:1046-1052.

5. Gessner C, Hammerschmidt S, Kuhn H, Seyfarth HJ, Sack U, Engelmann L, Schauer J, Wirtz H: Exhaled breath condensate acidification in acute lung injury. Respir Med 2003, 97:1188-1194.

6. Sack U, Scheibe R, Wotzel M, Hammerschmidt S, Kuhn $H$, Emmrich F, Hoheisel G, Wirtz H, Gessner C: Multiplex analysis of cytokines in exhaled breath condensate. Cytometry A 2006, 69:169-172.

7. Groshaus HE, Manocha S, Walley KR, Russell JA: Mechanisms of beta-receptor stimulation-induced improvement of acute lung injury and pulmonary edema. Crit Care 2004, 8:234-242.

8. Perkins GD, McAuley DF, Richter A, Thickett DR, Gao F: Benchto-bedside review: $\beta 2$-agonists and the acute respiratory distress syndrome. Crit Care 2004, 8:25-32.

9. Perkins GD, McAuley DF, Thickett DR, Gao F: The $\beta$-Agonist Lung Injury Trial (BALTI): a randomized placebo-controlled clinical trial. Am J Respir Crit Care Med 2006, 173:281-287.

10. Maris NA, de Vos AF, Dessing MC, Speck CA, Lutter R, Cansen $\mathrm{HM}$, Zee JS van der, Bresser P, Poll T van der: Antiinflammatory effects of salmeterol after inhalation of lipopolysaccharide by healthy volunteers. Am J Respir Crit Care Med 2005, 172:878-884.

11. Masclans JR, Barbera JA, MacNee W, Pavia J, Piera C, Lomeña F, Chung KF, Roca J, Rodríguez-Roisin R: Salbutamol reduces pulmonary neutrophil sequestration of platelet-activating factor in humans. Am J Respir Crit Care Med 1996, 154:529-532.

12. Bernard GR, Artigas A, Brigham KL, Carlet J, Falke K, Hudson L, Lamy M, Legall JR, Morris A, Spragg R: The American-European Consensus Conference on ARDS. Definitions, mechanisms, relevant outcomes, and clinical trial coordination. Am J Respir Crit Care Med 1994, 149:818-824.

13. The Acute Respiratory Distress Syndrome Network: Ventilation with lower tidal volumes as compared with traditional tidal volumes for acute lung injury and the acute respiratory distress syndrome. N Engl J Med 2000, 342:1301-1308. 
14. Murray JF, Matthay MA, Luce JM, Flick MR: An expanded definition of the adult respiratory distress syndrome. Am Rev Respir Dis 1988, 138:720-723.

15. Vincent JL, Moreno R, Takala J, Willatts S, De Mendonça A, Bruining $\mathrm{H}$, Reinhart CK, Suter PM, Thijs LG: The SOFA (Sepsisrelated Organ Failure Assessment) score to describe organ dysfunction/failure. On behalf of the Working Group on Sepsis-Related Problems of the European Society of Intensive Care Medicine. Intensive Care Med 1996, 22:707-710.

16. Gaston B, Hunt J: Measurement of exhaled breath condensate $\mathrm{pH}$ : implications for pathophysiology and monitoring of inflammatory airway diseases. In New Perspectives in Monitoring Lung Inflammation. Analysis of Exhaled Breath Condensate 1 st edition. Edited by: Montuschi P. Boca Raton, FL: CRC Press; 2005:73-84.

17. Vaughan J, Ngamtrakulpanit L, Pajewski TN, Turner R, Nguyen TA, Smith A, Urban P, Hom S, Gaston B, Hunt J: Exhaled breath condensate $\mathrm{pH}$ is a robust reproducible assay of airway acidity. Eur Respir J 2003, 22:889-894.

18. Moloney ED, Mumby SE, Gajdocsi R, Cranshaw JH, Kharitonov SA, Quinlan GJ, Griffiths MJ: Exhaled breath condensate detects markers of pulmonary inflammation after cardiothoracic surgery. Am J Respir Crit Care Med 2004, 169:64-69.

19. Czebe K, Barta I, Antus B, Vaylon M, Horváth I, Kullmann T: Influence of condensing equipment and temperature on exhaled breath condensate $\mathrm{pH}$, total protein and leukotriene concentrations. Respir Med 2008, 102:720-725.

20. Hunt JF, Erwin E, Palmer L, Vaughan J, Malhotra N, Platts-Mills TA, Gaston $\mathrm{B}$ : Expression and activity of pH-regulatory glutaminase in the human airway epithelium. $A m$ J Respir Crit Care Med 2002, 165:101-107.

21. Kostikas K, Papatheodorou G, Ganas K, Psathakis K, Panagou P, Loudikes $\mathrm{S}: \mathrm{pH}$ in expired breath condensate of patients with inflammatory airway diseases. Am J Respir Crit Care Med 2002, 165:1364-1370.

22. Walsh BK, Mackey DJ, Pajewski T, Yu Y, Gaston BM, Hunt JF: Exhaled-breath condensate $\mathrm{pH}$ can be safely and continuously monitored in mechanically ventilated patients. Respir Care 2006, 51:1125-1131.

23. Tate S, MacGregor G, Davis M, Innes JA, Greening AP: Airways in cystic fibrosis are acidified: detection by exhaled breath condensate. Thorax 2002, 57:926-929.

24. Dhingra VK, Uusaro A, Holmes CL, Walley KR: Attenuation of lung inflammation by adrenergic agonists in murine acute lung injury. Anesthesiology 2001, 95:947-953.

25. Perkins GD, Gao F, Thickett DR: In vivo and In vitro effects of salbutamol on alveolar epithelial repair in acute lung injury. Thorax 2008, 63:215-220.

26. Manocha S, Gordon AC, Salehifar E, Groshaus H, Walley KR, Russel JA: Inhaled beta-2 agonist salbutamol and acute lung injury: an association with improvement in acute lung injury. Crit Care 2006, 10:R12.

27. Morina $P$, Herrera $M$, Venegas $J$, mora $D$, Rodríguez $M$, Pino $E$ : Effects of nebulized salbutamol on respiratory mechanics in adult respiratory distress syndrome. Intensive Care Med 1997, 23:58-64.

28. Pesenti A, Pelosi P, Rossi N, Aprigliano M, Brazzi L, Fumagalli R: Respiratory mechanics and bronchodilator responsiveness in patients with the adult respiratory distress syndrome. Crit Care Med 1993, 21:78-83.

29. Wright PE, Carmichael LC, Bernard GR: Effect of bronchodilators on lung mechanics in the acute respiratory distress syndrome (ARDS). Chest 1994, 106:1517-1523.

30. Atabai K, Ware LB, Snider ME, Koch P, Daniel B, Nuckton TJ, Matthay MA: Aerosolized $\beta(2)$-adrenergic agonists achieve therapeutic levels in the pulmonary edema fluid of ventilated patients with acute respiratory failure. Intensive Care Med 2002, 28:705-711.

31. Mutlu GM, Koch WJ, Factor P: Alveolar epithelial beta 2-adrenergic receptors: their role in regulation of alveolar active sodium transport. Am J Respir Crit Care Med 2004, 170:1270-1275.

32. Sartori C, Allemann $Y$, Duplain $H$, Lepori M, Egli M, Lipp E, Hutter $D$, Turín $\mathrm{P}$, Hugli $\mathrm{O}$, Cook S, Nicod P, Scherrer U: Salmeterol for the prevention of high-altitude pulmonary edema. $N$ Engl $J$ Med 2002, 346:1631-1636.
33. Berg JT, Deem S, Kerr ME, Swenson ER: Hemoglobin and red blood cells alter the response of expired nitric oxide to mechanical forces. Am J Physiol Heart Circ Physiol 2000, 279:H2947-H2953.

34. Janssen LJ: Isoprostanes: an overview and putative roles in pulmonary pathophysiology. Am J Physiol Lung Cell Mol Physiol 2001, 280:L1067-L1082. 